\title{
Metafísica, Niilismo e Desconstrução nas empreitadas de Heidegger, Levinas e Derrida
}

\section{Fernanda Paixão ${ }^{1}$}

RESUMO: Pretendo realizar uma breve exposição da leitura de Heidegger do projeto niilista de Nietzsche e a relação entre metafísica e desconstrução sob a perspectiva do contraste entre o pensamento de Heidegger, Derrida e Levinas . Correlaciono igualmente a noção derridiana de phármakon como suplemento e a problematização da escritura com as empreitadas metafísicas no âmbito da desconstrução.

PALAVRAS-CHAVE: Metafísica. Niilismo. Escritura. Heidegger. Levinas. Derrida.

RÉSUMÉ : J'ai l'intention de présenter une brève exposition de la lecture que propose Heidegger au sujet du projet nihiliste de Nietzsche et de la relation entre la métaphysique et la déconstruction dans la perspective du contraste entre la pensée de Heidegger, Derrida et Levinas. Je mets également en corrélation la notion derridienne de pharmakon comme supplément et la problématisation de l'écriture avec les entreprises métaphysiques dans le domaine de la déconstruction.

MOTS CLÉS : Métaphysique. Le nihilisme. L'Écriture. Heidegger. Levinas. Derrida.

« Le monde crée en moi le lieu de son accueil » Jean Wahl

\section{Heidegger leitor de Nietzsche e a metafísica em Levinas e Derrida}

Ao acompanharmos o pensamento de Heidegger, a diferença entre ser e ente é a própria diferença ontológica: a história da metafísica é a história da entificação como alma, como tentativa de classificar o ser. Na metafísica, o ser é tratado como ente, o ser é objetificado e encontramos a história da metafísica como história do esquecimento do ser. O projeto niilista de Nietzsche, na leitura de Heidegger, quer

\footnotetext{
${ }^{1}$ E-mail: fernandapaixao@gmail.com.
} 
fazer o traço desaparecer e o desvelamento tornaria possível a superação da metafísica enquanto instância objetificadora do ser. A Ge-Stell, conceituada como a estranha força que desaba as regiões, transforma tudo o que é ordenável e aquilo que está à disposição para receber a ordem ou aquilo que não pode se ausentar. $A$ Bestand corresponde a ao que está reservado, conscrito e que está à disposição da Ge-Stell. Nesse entendimento, o dispositivo (positionality, Ge-Stell ) dispõe a disponibilidade (standing reserve, bestand ) (Heidegger, 2003). Nessa concepção, a Ge-Stell adviria da tecnologia, como essência da técnica, o que seria o não-humano. Neste ponto, o filósofo posiciona-se como anti-prometeísta: o ser está sempre em perigo, assim como propalava Rilke, "a nossa natureza não nos protege" ou não há lugar seguro.

No entendimento de Heidegger, a metafísica da subjetividade abre a possibilidade de representação. A realidade que tudo expõe representa esta exposição. O mundo é representação, mas quem faz a representação? Que dizer disse isso? O dizer está atrás do mapa - já que todo mapa mundi será refém de um dizer - o que traz um entrave na representação. A noção do mundo representável é a ideia de representação de algo que já está revelado. Toda história do ser é a do ser humano, que se aproxima de um já revelado. A existência é exposição, a substância persiste em uma coisa que passa pela mudança de sua essência básica.

A crítica de Levinas à ontologia de Heidegger surge no sentido de introduzir a metafísica como noção de exterioridade. O Dire e Dit levinasianos correspondem à inteligibilidade e para Levinas, o dito é o que se essencializou, se entificou. O ser estaria próximo do dito, enquanto que o dizer é aquilo que instaura a diferença. $O$ dizer precede o dito, no dizer não se esgota o dito. No dizer reside o excesso, a ausência de consciência como abertura para o infinito. No Dire e no Dit, o trabalho de inteligibilidade não pode ser extraído, o que instaura a responsabilidade é o dizer, pois o Dit é órfão. O outro sempre excede as possibilidades do ser, a relação com outrem não nos afeta a partir de um conceito, o compreender o outro já é falar-lhe. No encontro com o outro não exerço poder sobre ele, nem introduzo um horizonte prévio, eu encontro seu rosto. O outro é aquilo que eu não sou, o outro é paradoxal, suplementar a mim. A responsabilidade pelo outro é infinita (Levinas, 2008).

Levinas faz a ruptura com o ontologismo. A subjetividade para Levinas não responde à representação, mas à substituição, o outro me substitui, como suplemento. Para Levinas, a recorrência ocorre quando saio de mim, quando o outro me substitui pois quando volto a mim não sou mais o mesmo. O conceito de substituição é aquilo que não sou. A recorrência não rompe com a representação, a recorrência ocorre 
como interrupção em relação à metafísica da subjetividade. Levinas diz que o eu é refém do outro. O outro é uma incumbência infinita e sempre um rastro, o outro não é presença, mas um rastro que se inscreve em mim.

A metafísica de Heidegger não contém toda a exterioridade, é a trama do mesmo. Na exterioridade não preciso responder ao outro, sou separado dele e não há relação de dependência: depois de agir para o outro, eu volto para mim, eu tenho a minha casa. Mas para Levinas, eu ajo pelo outro sem ser o outro, escapo do meu ser, a partir da ideia do excesso, apresento a insuficiência de estar preso ao meu ser, o outro é um traço que me afeta, não há metafísica da subjetividade, pois ela não é única, mas plural: o ego cósmico da vontade de poder desaparece em Levinas. A subjetividade é passividade, abertura para o outro, pura receptividade afetada pelo anárquico, pelo outro que se inscreve na consciência como estrangeiro. Nessa abertura para o outro deve se desfazer a tematização, a aproximação do outro é anterior à consciência, uma aceitação de fraternidade. O sujeito não surge do logos, mas do contato. Levinas posiciona o outro na diferença, contra o interessamento: somos vulneráveis ao outro, num jogo de eterna responsabilidade e de substituição; o outro me interpela, o mesmo não está em repouso, a identidade não se reduz do mesmo, o tempo não dura senão pela paciente espera pelo outro.

A introdução do conceito de suplemento por Derrida complementa Levinas nas empreitadas metafísicas no âmbito da desconstrução. Para Derrida, o ser é rastro, é a própria instauração da diferença. A presença é sempre uma inscrição, a diferença na escritura é a marca que você faz, o ser é um traço, o ser está por trás do presenciamento (Derrida, 2013). A ausência também é personagem da metafísica da presença e o rastro como suplemento surge como estratégia antiniilista. O suplemento é o messias, é o que vai salvar e lhe transformar naquilo que você não era. É possível extrair a inteligência, mas não a inscrição: não se extrai a inteligibilidade e a coloca num robô, pois mesmo na fala há o dizer. O texto não pára, a inteligibilidade é polifônica. Nesse entendimento, nunca estamos na presença, uma vez que tudo é derivado, simulacro. A desconstrução é infinita, cada inscrição, cada suplemento é transformação do original. Não tem mais próximo, não há mais para onde fugir, cabe suplementar a presença rarefeita, pois a presença é refém do suplemento: a coisa quando suplementada será outra coisa des-naturada. Assim a desconstrução mina a univocidade das representações.

O mundo está sendo substituído pela Ge-Stell, diagnóstico do nada e anfitrião de todas as coisas. É no nada que as coisas se abrigam, considerando que Derrida não pensa em termos de abrigo pleno. Para ele há um vão entre trace/rastro (dizer) e presença (dito). Extrair o dito de um dizer é testemunho. Os rastros da presença são 
desconstrução. O ser não é pleno, a presença não é plena, o dizer não se consuma no dito, não prescinde do dito; o dizer é a marca do outro que precede e é independente do que foi dito. O dizer é inalcançável, pois é ereignis incompleta.

Derrida invoca o conceito de hospitalidade, mas ao mesmo tempo compreende o estar no mundo como imposição discursiva, marcada por discursos, mas há um ponto que escapa a esta imposição, um ponto de fuga. O trabalho do pensamento ou da escritura é o de localizar este ponto, mas localizar não é captar, pois essa é uma busca impossível. Talvez chegar o mais próximo possível, mas jamais captar. A desconstrução restringe as operações discursivas que apontam para o ponto de fuga, mas como o pote de ouro na base do arco-íris é impossível tocá-lo. A différance é o que está em ponto de fuga, o tocar seria uma operação em direção aquilo que não é, ou o inexistente. Para Derrida, o lapso da metafísica da presença (ou a presença) só se faz presente na diferença. Não se pode exigir que o outro seja produto de reconhecimento, pois a presença do outro é sempre fantasmagórica. O original não é mais o mesmo após o traço.

\section{Metafísica e escritura: pharmakon como veneno ou remédio?}

Derrida elabora sua crítica a Fédron (Sócrates por Platão) tomando Heidegger como referência (Derrida, 2005). Segundo Sócrates, o texto remedia a urbanidade, altera o curso das coisas. Em sua concepção, o texto não explica o que ele quer dizer quando perguntado, pois a princípio se cala, não distingue a quem deve ou não falar. Segundo Platão em Fédron, a escrita surge como lócus órfão, não há ninguém para defender, não há presença, o texto é órfão. O autor não tem voz, a escrita suplementa a voz: a voz pode ser interpelada, a escrita não. O problema da escrita é que ela fala para qualquer um que chega e abre o livro. Assim a Phármakon é intervenção artificial que poderia ser evitada ao máximo.

Derrida usa da orfandade do texto para analisar o rastro. É da natureza do excesso ter o suplemento. A Phármakon precisa intervir na physis de fora, ela afeta o sistema e o curso natural das coisas, é artificial. O que se opõe à physis é phármakon. A escritura é suplente da voz, extrair a inteligibilidade é extrair a voz das coisas e não das coisas escritas. Phármakos está em bestand porque ela não sabe para quem está destinada. A escritura é uma diáspora, uma disseminação, um excesso, um filho perdido. O ser humano a dissemina por toda a parte na metáfora da escritura como jogada ao vento. A escritura é produto do parricídio. E o parricídio é importante, pois introduz o outro, o estrangeiro, pela filosofia. Platão escreve, mas com estrutura de 
diálogo. A escritura permite suplemento, sempre vai existir o suplemento e Platão trai a escritura escrevendo. O livro é tratar a escritura como discurso oral.

Assim Derrida entende que o suplemento da escritura deve ser rigorosamente prescrito, mas pela verdade que precede qualquer fala ou a precedência da escrita. $\mathrm{O}$ texto só vai revelar se for adicionado. O efeito da leitura, da fricção de textos é uma pista para desconstrução. Cada vez que se lê, se cria uma nova verdade. O texto é desprovido de verdade, o texto precisa de um pai, pois não pode se defender sozinho. Como noção de suplemento, Derrida apresenta Thot como deus da noite que substitui o Há, deus do sol, suplementando sua ausência. A escritura se passa por alguém, mas não é esse alguém, é um jogo, supre uma falta. O texto é um substituto da ausência da voz. A escritura é a sobrevida, além da morte. O fogo precede o aquecimento. A hermenêutica pensa a verdade do texto, a desconstrução pensa na justiça do texto. A leitura é um ato ético, a ética traz a vida algo morto, adição como adoção, é passagem do não ser ao ser. Ler é trazer a presença. Mas a escritura é colocada em xeque. Acrescentar é dar a ler, ler é adicionar. Leitura é um exercício de justiça - o leitor vivifica a obra, a presença traz uma verdade.

A técnica fecha o âmbito da desconstrução, se associada à voz, vence a batalha. A escritura é o sepulcro da verdade, a voz que desvela. Na escrita só há vestígios, rastros, nada está garantido. A arquiescritura precede a voz, para Sausurre, a estrutura básica da fala é a escrita, para entender a estrutura do discurso é preciso pensar na língua escrita. Saussurre afirma que o significante está associado a um sistema de diferenças. O significado independe do significante, o ultraestruturalismo aplica o estruturalismo para além do significante. Na metafísica da presença, o sistema de diferenças é a escritura e os significantes e significados são marcados pelo rastro, que faz com que eles se apresentem. Derrida abre a possibilidade para o traço (rastro) como ontologia. O traço é o ser riscado, aquilo que torna a presença possível na cultura e na natureza. A grafia implica a insistência de um rastro constituído, abertura para exterioridade, aquilo a partir de um vir a ser é constituído. O suplemento não pensa na volta ao originário, a presença é instada pelo rastro, que é produto do suplemento.

Na perspectiva heideggeriana, a fala já é maquinal, a escritura aparece como consignação, é confiada a alguém que vai guardar, ao mesmo tempo ela não está na physis, é um suplemento, um phármakon. Segundo Heidegger, a voz é parricídio, rastro que cai no horizonte transcedental. Nesse sentido, o fundante

é a ausência. Já Levinas compreende a fala como direcionada ao convencimento.

O que é próprio da escrita é o que ela não é (a fala). A escrita trai a metafísica, 
procura ser o arquivo da inteligibilidade extraída, a inteligibilidade está sempre submetida a um Dire. Mas para Derrida, está vinculada a um Lire, quando a GeStell virar uma bula, terá que ser lida².

\section{Referências bibliográficas}

HEIDEGGER, Martin. Caminhos de floresta. Fundação Calouste Gulbenkian. Lisboa, 2012.

HEIDEGGER, Martin.. Bremen and Freiburg lectures: insight into that which is and basic principles of thinking. Bloomington, IN: Indiana University Press, 2012. HEIDEGGER, Martin.. Time and Being. Translated by Joan Stambaugh. New York: Harper \& Row Publishers, 1972.

LEVINAS, Emmanuel. Autrement qu'être ou Au-delà de l'essence. Livre de Poche, 2008.

DERRIDA, Jacques. Da Gramatologia. São Paulo: Perspectiva, 2005.

DERRIDA, Jacques. Margens da Filosofia. Campinas: Papirus, 1991.

DERRIDA, Jacques. A farmácia de Platão. São Paulo: Iluminuras, 2005.

Recebido em outubro de 2019 Aceito em maio de 2020

\footnotetext{
${ }^{2}$ Agradeço e credito os ensinamentos deste artigo ao professor Hilan Bensusan, do Departamento de PósGraduação em Filosofia da Universidade de Brasília
} 